\title{
Passively synchronized dual-wavelength Q-switched lasers
}

Janousek, Jiri; Tidemand-Lichtenberg, Peter; Mortensen, Jesper Liltorp; Buchhave, Preben

Link to article, DOI:

10.1109/QELS.2005.1548964

Publication date:

2005

Document Version

Publisher's PDF, also known as Version of record

Link back to DTU Orbit

Citation $(A P A)$ :

Janousek, J., Tidemand-Lichtenberg, P., Mortensen, J. L., \& Buchhave, P. (2005). Passively synchronized dualwavelength Q-switched lasers. Poster session presented at 2005 Quantum Electronics and Laser Science Conference, Baltimore, MD, United States. https://doi.org/10.1109/QELS.2005.1548964

\section{General rights}

Copyright and moral rights for the publications made accessible in the public portal are retained by the authors and/or other copyright owners and it is a condition of accessing publications that users recognise and abide by the legal requirements associated with these rights.

- Users may download and print one copy of any publication from the public portal for the purpose of private study or research.

- You may not further distribute the material or use it for any profit-making activity or commercial gain

- You may freely distribute the URL identifying the publication in the public portal

If you believe that this document breaches copyright please contact us providing details, and we will remove access to the work immediately and investigate your claim. 


\title{
Passively synchronized dual-wavelength Q-switched lasers
}

\author{
Jirí Janousek, Peter Tidemand-Lichtenberg, Jesper L. Mortensen, Preben Buchhave \\ Department of Physics. Technical University of Denmark. DK-2800 Lyngby. Denmark \\ Corresponding author: tidemand@fysik.dtu.dk
}

\begin{abstract}
We present a simple and efficient way of generating synchronized Q-switched pulses at wavelengths hundreds of nanometers apart. This principle can result in new pulsed all-solid-state light sources at new wavelengths based on SFG.

C2005 Optical Society of America

OCIS codes: (140.3580) Lasers solid-state, (140.3540) Lasers, Q-switched
\end{abstract}

\section{Introduction}

Recent interest in efficient diode-pumped solid-state pulsed lasers in the yellow spectral region has led to a number of interesting configurations, typically based on sum-frequency mixing of two pulsed infrared lasers. To obtain efficient conversion in the nonlinear process the two laser pulses have to be synchronized very carefully. A convenient way of doing this is by generating the two pulses in a common cavity using an active Q-switch acting at both wavelengths simultaneously [1].

In this paper it will be shown that it is possible to obtain nicely synchronized dual-wavelength pulses using a passive Q-switching material in a common optical cavity. Previously, V:YAG has been shown to work as a saturable absorber at both $1064 \mathrm{~nm}$ and $1342 \mathrm{~nm}$ [2,3]. The material works at both wavelengths simultaneously, saturating the same energy state. The material can therefore be used as a passive Q-switch in a common path of two lasers operating at $1064 \mathrm{~nm}$ and $1342 \mathrm{~nm}$, respectively, leading to synchronized Q-switching of the two lasers [4]. The synchronized state of operation is described both theoretically and experimentally.

\section{Setup for passively synchronized operation of two infrared lasers}

The setup is shown in Fig. 1. We used two Nd:YVO -based folded cavity lasers operating at $1064 \mathrm{~nm}$ and $1342 \mathrm{~nm}$, respectively. The two laser resonators are designed to share a common beam path, in which the V:YAG saturable absorber is positioned. Each laser has a beam waist radius of approximately $80 \mu \mathrm{m}$ at the position of the absorbing V:YAG material. The $0.5 \mathrm{~mm}$ long V:YAG crystal supplied by Crytur Ltd. has a small-signal transmission of $4 \%$ and $10 \%$ at $1064 \mathrm{~nm}$ and $1342 \mathrm{~nm}$, respectively.
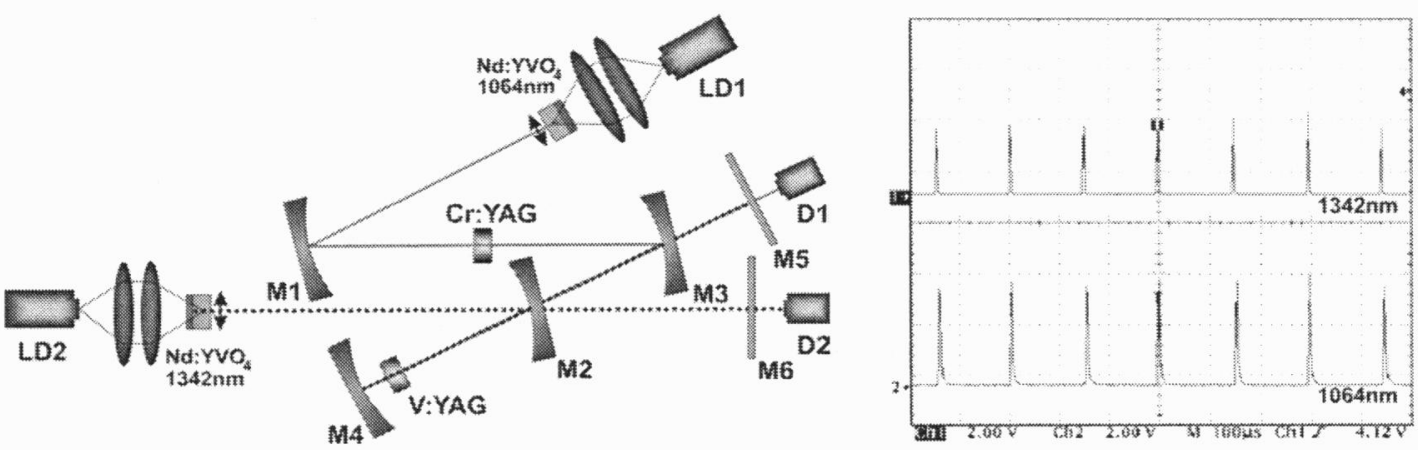

Fig. 1. Setup for passively synchronized Q-switched $\mathrm{Nd}_{\mathrm{YVO}} \mathrm{YV}_{4}$ lasers oscillating at 1064 and $1342 \mathrm{~nm}$ respectively To the right the generated pulses are shown; upper trace is the $1343 \mathrm{~nm}$ laser, lower trace is the $1064 \mathrm{~nm}$ laser. 


\section{JTuC29}
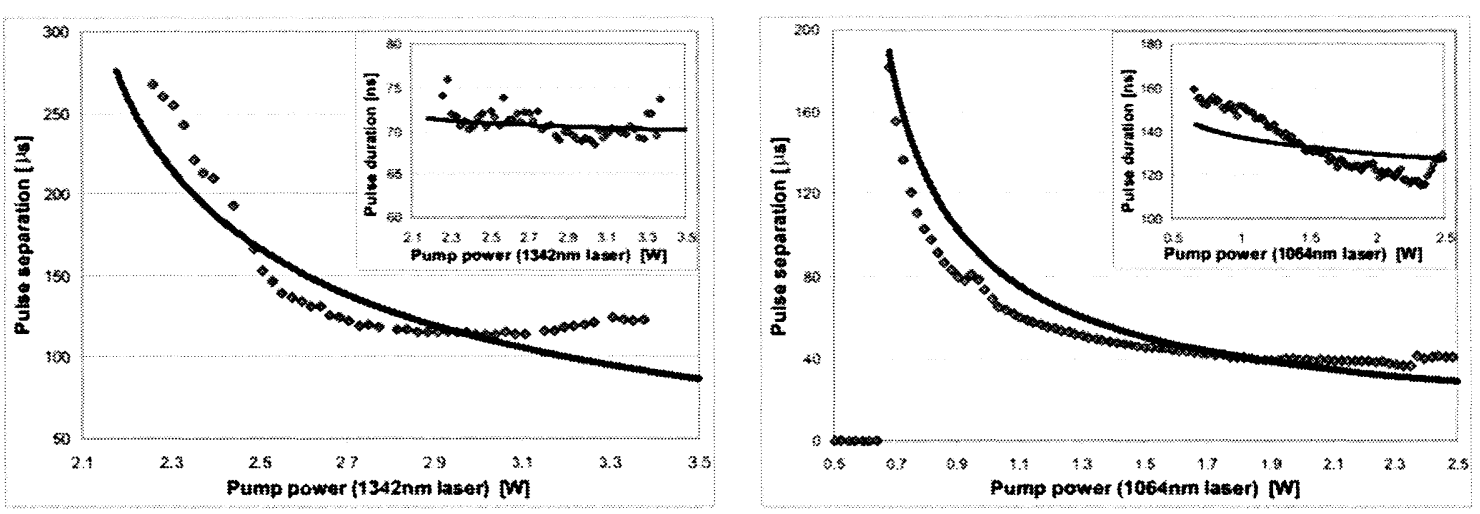

Fig. 2. Measurements and simulations of pulse separation and pulse duration. Left figure shows the results for the $1342 \mathrm{~nm}$ laser using V:YAG as the saturable absorbing material. The right figure shows the results for the $1064 \mathrm{~nm}$ laser, using Cr:YAG in combination with V:YAG. The insert on both figures shows the measured and simulated results for pulse separation.

An additional $10 \%$ saturable absorbing Cr.YAG material is inserted into the $1064 \mathrm{~nm}$ laser. This is used in order to obtain approximately the same repetition rate of the two lasers free running. The right part of the figure shows a measurement of the pulses generated using this setup.

The left graph in fig. 2 shows measured (diamonds) and simulated (solid line) pulse separation as a function of the pump power for the $1342 \mathrm{~nm}$ laser. The insert in the figure shows the corresponding measured and simulated pulse durations. Clearly there is some difference between the measured and the simulated curve. However, this is mainly caused by thermal lensing in the V:YAG saturable absorber. The V:YAG material is modeled by a set of coupled differential equations describing the populating of the various energy levels, including excited state absorption. The right part of fig. 2 shows a corresponding measurement on the $1064 \mathrm{~nm}$ laser using the combination of the two saturable absorbing materials. Again both measurements and modeled data for the pulse separation and pulse duration are shown. There is a quantitative agreement between the measured and modeled results, however, thermal lensing influences the measurements. Clearly the pulse separation ought not be increasing at increasing pump power as is seen at higher pump powers.

\section{Measured states of synch ronization}

Figure 3 shows measured pulse separation of the $1342 \mathrm{~nm}$ laser as a function of diode pump power, when the 1064 $\mathrm{nm}$ laser is pumped by $1.0 \mathrm{~W}$. The pulse separation of the $1064 \mathrm{~nm}$ laser is approximately $120 \mu \mathrm{s}$. It is clearly seen, that the pulses from the two lasers lock together as the pump power is varied. If the pulse separations of the two lasers have nearly an integer ratio, they synchronize due to the coupling in the V:YAG saturable absorber. The insert in the figure shows the corresponding model results.

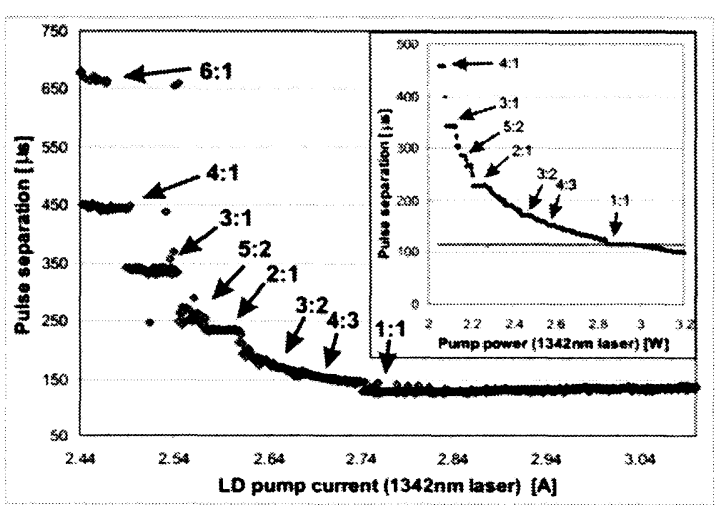

Fig. 3. Measurement of pulse separation of the two lasers. The $1064 \mathrm{~nm}$ laser is pumped at constant power. The $1342 \mathrm{~nm}$ laser pump power is increased along the $x$-axis. The insert shows the corresponding simulation.

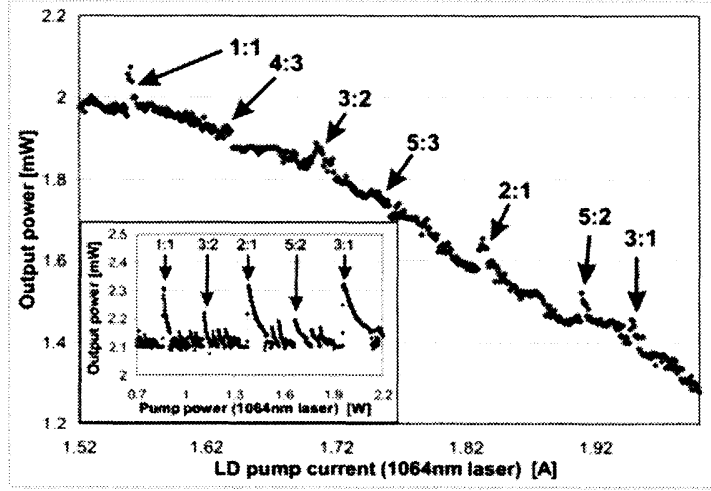

Fig. 4. Measurement of average power of the $1342 \mathrm{~nm}$ laser varying the pump power of the $1064 \mathrm{~nm}$ laser. The insert shows the corresponding simulated results. The pump power of the $1342 \mathrm{~nm}$ laser is fixed at $2.6 \mathrm{~W}$. 


\section{JTuC29}

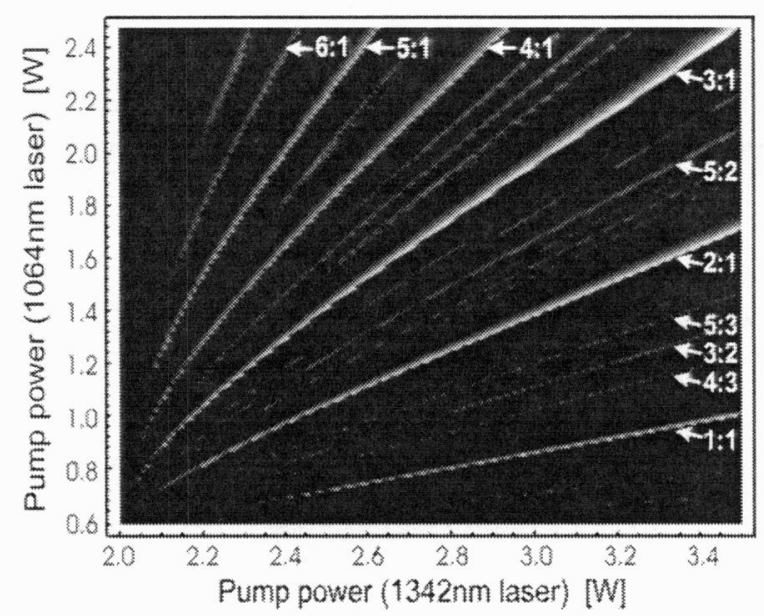

Fig. 5. Calculated pulse overlap as a function of pump power in the two lasers.

When the first of the two lasers reach threshold, it starts to build up a circulating field in the resonator saturating the V:YAG material. This results in reduced losses for the second laser, which thereby reaches threshold. The laser that reaches the threshold first thereby sets the repetition rate of the system. The pulse duration of the first laser is increased due to bleaching of the absorber by the second laser.

Figure 4 shows the average power of the $1064 \mathrm{~nm}$ laser as the pump power of the $1342 \mathrm{~nm}$ laser is varied. The overall decrease in power is probably due to thermal effects in the V:YAG material, as the circulating power at 1342 $\mathrm{nm}$ is increased. However, the interesting feature of this graph is the small spikes corresponding to states of synchronization of the two lasers. When the two lasers are synchronized they work together bleaching the saturable absorber, and therefore the losses for both lasers are decreased corresponding to an increase in average power for both wavelengths. The insert shows the modeled results.

Figure 5 shows modeled data for the pulse overlap between the two lasers, as a function of the diode laser pump power for the two lasers. This graph is calculated as the product of the power of the two lasers, divided by the number of synchronized pulses per second. This therefore corresponds to the pulse energy of generated yellow light in a subsequent sum-frequency generation process.

\section{Future improvements on the system}

The next step using this setup is to increase output coupling from the system, maintaining the strong coupling between the two generated wavelengths. Also we need to decrease the thermal lensing in the V:YAG material by using a longer crystal with a reduced doping level. Finally we need to make SFG between the generated pulses.

\section{References:}

[1] Y. F. Chen and S. W. Tsai, "Diode-pumped Q-switched Nd:YVO4 yellow laser with intracavity sum-frequency mixing", Optics Lett. 27, 397-399 (2002).

[2] A. M. Malyarevich, I. A. Denisov, K. V. Yumashev, V. P. Mikhailov, R. S. Conroy, and B. D. Sinclair, "V:YAG - a new passive Q-switch for diode pumped solid-state lasers", Appl. Phys. B 67, 555-558 (1998).

[3] A. Agnesi, A. Guandalini, G. Reali, J. K. Jabczynski, K. Kopczynski, and Z. Mierczyk, "Diode pumped Nd:YVO4 laser at 1.34 $\mu$ m Qswitched and mode locked by $\mathrm{V}^{3+}$ :YAG saturable absorber", Optics comm. 194, 429-433 (2001).

[4] P. Tidemand-Lichtenberg, J. Janousek, Radek Melich, Jesper L. Mortensen and P. Buchhave, "Synchronization of 1064 and 1342 nm pulses using passiv saturable absorbers", Optics Comm. 241, 487-492 (2004). 